\title{
Improvement of Project Management Using Accelerated SAP Method in the Odoo ERP
}

\author{
Supriyono $^{1}$, Sutiah $^{2}$ \\ \{priyono@ti.uin-malang.ac.id ${ }^{1}$, sutiah@pai.uin-malang.ac.id²
${ }^{1}$ Informatics Engineering Department, Faculty of Science and Technology, Universitas Islam Negeri (UIN) Maulana Malik Ibrahim Malang, Indonesia
${ }^{2}$ Islamic Education Department, Faculty of Tarbiyah and Teaching Training, Universitas Islam Negeri (UIN) Maulana Malik Ibrahim Malang, Indonesia

\begin{abstract}
Project management is the most important part of software development projects. On the project management of software development can use one module in Odoo ERP. One of the modules of ERP Odoo used in this research is a module project. Project management is a way of regulating discrete work to achieve specific objectives by managing the workings of a team of software developers who depend on the software development process. The methods used in this research is Accelerated SAP (ASAP). ASAP is a framework that applied on the project management method to improve efficiency in the management of the project. Development of a method of ASAP can be implemented in software project development planning so that the software development process can be made more effective and efficient as well as producing good quality products. The results of the process improvement project management will be shown with $89 \%$ effectiveness rate.
\end{abstract}

Keywords: Project management, Accelerated SAP, Odoo ERP.

\section{Introduction}

The development of software implemented in the company has a pretty good impact on the company. Some national scale companies implement ERP in data management in companies. ERP is software that can be integrated with software in the company. The software development process that has a high degree of complexity requires a reliable development team and a good quality project management mechanism. The application of the methodology in software project management can use Accelerated SAP because the framework used is able to implement ERP in an integrated manner [1]. The current issue of ERP is how to adopt ERP in business processes within a company rather than doing development from the start until the software is implemented in the company. In project management, software needs to be well prepared, starting from the needs analysis stage to the maintenance process. The main issue in software project management is the need for a relationship between the developer team and stakeholders in bringing together opinions at the stage of software development. Accelerated SAP has several stages used including Project Preparation, Business Blueprint, Realization, Final Preparation, Go Live \& Support [2].

The stages of Project Preparation for the implementation of Accelerated SAP are the initial stages in gathering information. The decision-making process at the stage of Project Preparation is crucial in determining the management of software development projects. Stage 
of Business Blueprint is the stage that is carried out when doing documentation in software project management. The phases carried out at this stage include a schedule of software developer teams involved in the stages of developing software. The Realization Phase is the next stage that is carried out after the business blueprint stage is completed. This stage performs identification requirements that are tailored to the results of the engineering requirements process based on real facts found when analyzing system requirements. Final Preparation Stages are the stages carried out in the testing and finishing process in project management. This stage affects the results obtained when the software project is in accordance with the design stages. Go Live \& Support Stages is the final stage of this software project that can be implemented in the maintenance process so that it makes it easier for the software development team to process the developer.

Other research that discusses the use of the Accelerated SAP method in adopting the module on Odoo ERP resulted in quite good recommendations. The implementation of Odoo ERP in the accounting module is able to handle the accounting process in a company. Financial statements that are quite complicated because they have a high level of complexity can be solved by adopting the accounting module in Odoo ERP [3]. The level of complexity is quite high in monitoring, control in software project management needs the right method so that the software project management process can produce satisfactory output. One method used in software management includes using the Accelerated SAP method. The risks faced in the management of software development projects often occur. Therefore, risk management is needed for minimizing the risks faced. One of the things that can be done is by carrying out the stages of risk identification, carrying out risk management that has a fairly high threat impact and analyzing the impact of the threats posed by the project management [4].

The way to adopt Odoo ERP to carry out project management is to implement the project module contained in Odoo ERP. ERP implementation needs to identify problems in companies that will implement ERP. Recommendations generated in project management can reduce failure in ERP implementation. To measure the failure rate and the level of success in software development, it is necessary to collaborate between the client and information technology consultants. Among the factors that influence the level of success in software, management is the existence of project planning, commitment from the client, communication between the software developers [5]. The method released by SAP is an SAP method approach that is integrated with the Agile method. Sprint and Scrum are used in five phases of the Accelerated SAP development method. The Accelerated SAP method has actually adopted the entire method developed at this time. Previous research shows the results of comparative studies between methodologies in ERP implementation in companies that are in accordance with the Accelerated SAP method in the ERP implementation phase [5]. The development of the majority of software is not in accordance with the planning in the development of software projects. Many companies suffer losses because companies do not have a good relationship between project managers and developer staff. The team of software developers and stakeholders need to learn more about software documents to get the knowledge that users want [6]. Poor coordination between the software development team will make it take a long time to develop the software generated from the planning deadline. Information in software development is very important to support the continuation of the stages of developing software [7].

Based on these problems, a company in the field of software development requires a system that can manage the timeline, coordinate the software developers, and monitor activities in software development. A system that automates and integrates all module business areas known as ERP systems. ERP systems are used to integrate various data sources 
and processes, such as process management, scheduling, and monitoring reports on the outcome of a project. ERP provides a system that has a variety of modules that can provide solutions to work units or in business activities of the company, namely Odoo 10. Odoo can support the company's business processes, especially in management processes because it can manage activities in the production of software development that can help companies improve production performance. Then it can be applied to management software using Odoo 10 on project management and development. So that it is expected to provide evaluation and the best solution to the process.

Other research discusses the Distributed Software Project Management Tool (DSPMtool) in software development project management. The results obtained show the software project prototype with an object-oriented design approach [8].

\section{Literature Study}

Literature studies conducted based on research are related to the topics raised in the following research problems. From several research studies, several stages of the research process were formulated and the problem-solving mechanism found.

\subsection{Software Project}

The project to be developed must be analyzed by software requirements. From the results of engineering, requirements will be produced by software specifications developed. The results of the integrity analysis of the project software will be carried out the task definition process for each software developer.

\subsection{Project Preparation}

At this stage make initial planning and preparation for implementation. Things that need to be done such as determining the scope. Planning research is conducted to determine the objectives of the study. Furthermore, collecting the required data, data collection is obtained through literature studies and field studies. Literature study in the form of literature on the concept of implementing ERP.

\subsection{Business Blueprint}

The step that needs to be done is making the As Is document or the current condition in the form of a flowchart, To Be, analysis gap and risk. At this stage, start designing how the current condition of the company is through a flowchart description of the company's business processes. Then at this stage, the company's business process is adjusted to the module on Odoo.

\subsection{Realization}

At this stage, it aims to implement ERP based on the needs and business processes contained in the Business Blueprint. 


\subsection{Final Preparation}

Things that need to be done are user acceptance testing (UAT), training for users, and migrating data.

\subsection{Go-Live and Support}

At this stage, it was marked by the start of ERP usage in the company. The system needs to be monitored to know and anticipate problems that might occur so that assistance can be done immediately.

\section{Method}

The quality of the software depends on the project management process carried out from the initial stage to the final stage. A carefully planned and mature Software Project will produce high-quality products. And vice versa, the software project planned with bad management software will produce low-quality software products. The software project has several stages including planning and defining tasks. The following research has several stages of research. The methodology used in the following research is as shown in Figure 1. In Figure 1

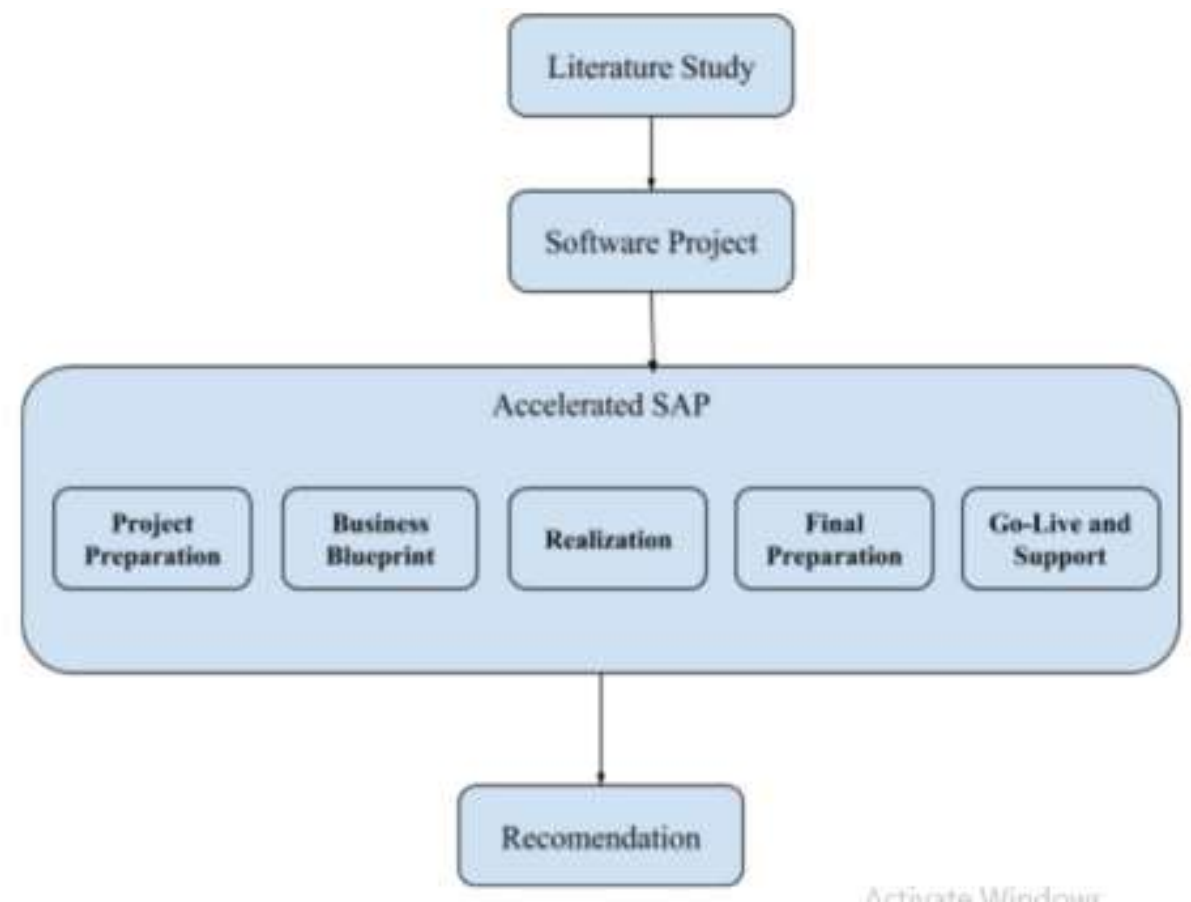


Figure. 1. Stages Of Research

\section{Result and Discussion}

The following research contains several management mechanisms for software projects using the Accelerated SAP method. The following is the result of Accelerated SAP implementation shown in table 1 .

Table 1. Implementation Accelerated SAP

\begin{tabular}{lcl}
\hline Stages & Software Development \\
\hline Project Preparation & - & Analysis \\
& - & Learning Media Needs Software \\
& - Implementation strategy \\
Business Blueprint & - Developer Team Formation \\
& - Gefine objectives and objectivity \\
& - Documentation \\
Realization & - Management of Software Systems \\
& - Configuration Integration \\
& - Unal Configuration \\
Final Preparation & - Unit testing \\
& - Training Application Users \\
Go-Live & - Integration Testing \\
Support & - Support \\
& - Monitoring \\
\hline
\end{tabular}

Schedule project work can be shown in Figure 2. schedule project work can be shown in Figure 2. Schedule projects include activities conducted in developing e-learning management software at the Islamic State University Maulana Malik Ibrahim

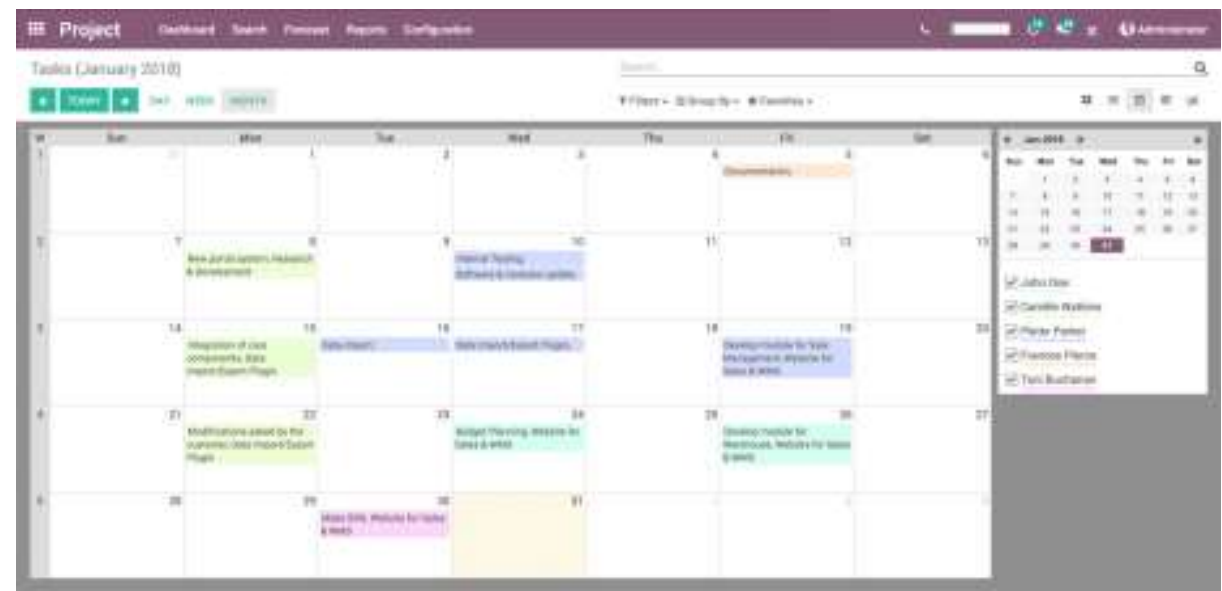


Figure 2. Schedule Software Project

Planning software can be shown in figure 3. The planning software was designed based on a case study of software development for e-learning.

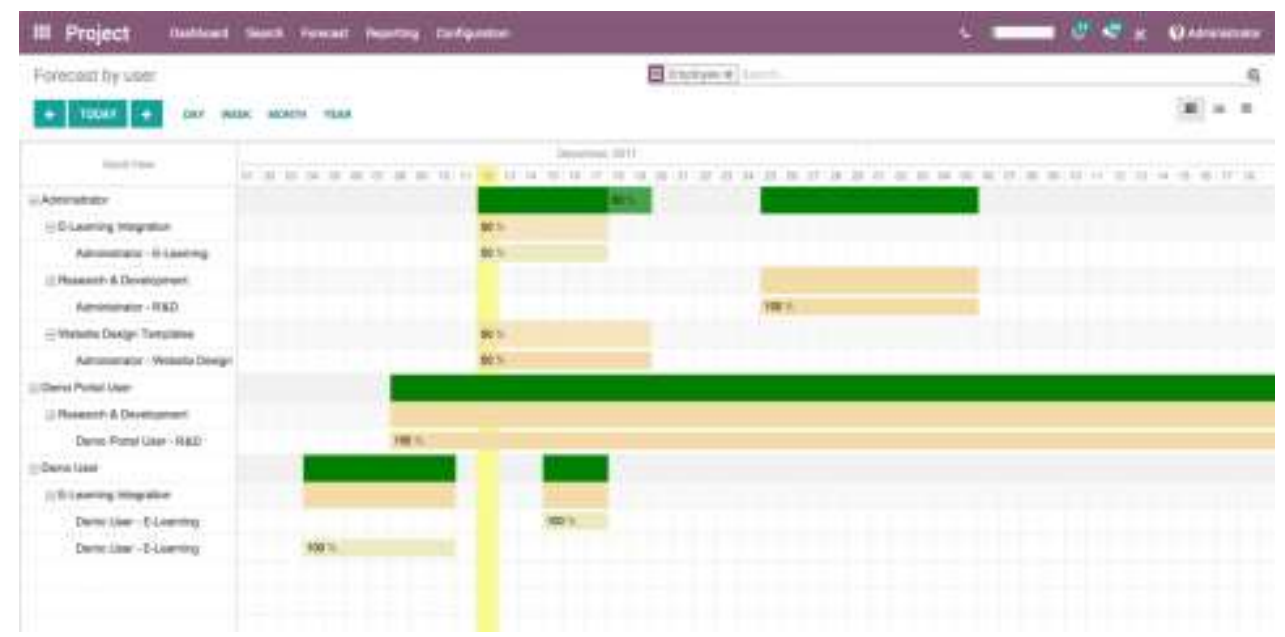

Figure 3. Software Planning

The level of timeliness and suitability of the results of this study can be seen from the results of the timeline analysis of the work on software projects at IT Consultant Malang in shown Table 2 .

\begin{tabular}{lc}
\hline Item Project & Timeline (Day) \\
\hline Requirements Analysis & 40 \\
System Design & 30 \\
Implementation & 20 \\
Testing & 15 \\
Deployment & 10 \\
Maintenance & 30 \\
\hline
\end{tabular}

Table 2. Project Work Timeline

Realization of project work can be seen in table 2 which shows significant results so that in the management of software projects more effective and efficient because it can be measured.

\begin{tabular}{ll}
\hline Item Project & Timeline (Day) \\
\hline Requirements Analysis & 35 \\
System Design & 55 \\
Implementation & 15 \\
Testing & 12 \\
Deployment & 14 \\
Maintenance & 31 \\
\hline
\end{tabular}

Table 2. Project Implementation Realization 
These results follow the conditions of stakeholders and conditions in the field. In detail, it can be seen as in Figure 2 which shows the timeline stages of the work on the software project.

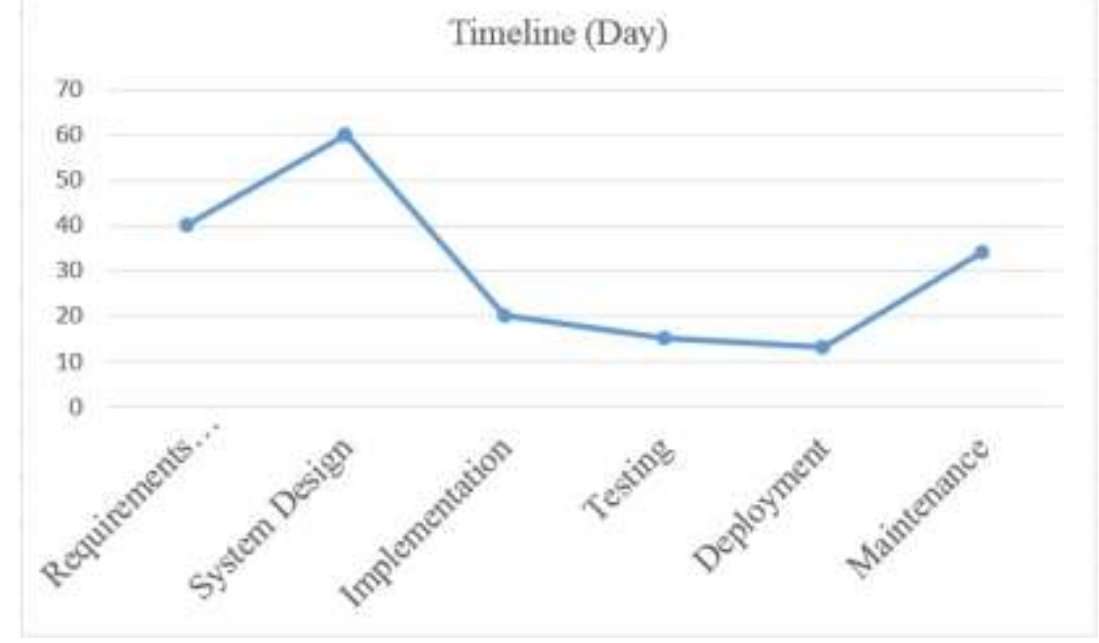

Figure 4. Project Work Timeline

The realization of the project work process can be seen as shown in Figure 3. The results of the graph are displayed in each phase of the process carried out.

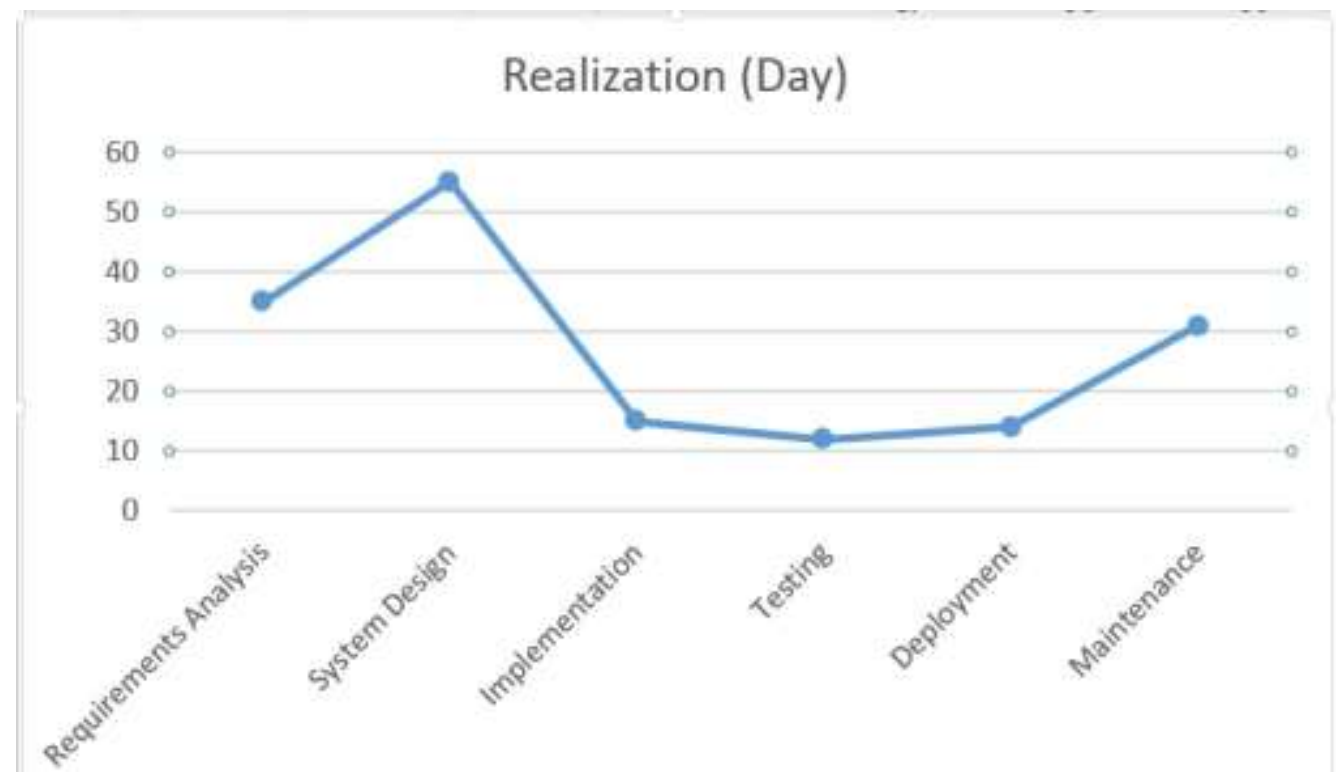

Figure 5. Project Realization Timeline 


\section{Conclusion}

The following research can be concluded that the Accelerated SAP method has a level of efficiency and effectiveness in the management in developing e-learning management software at the Islamic State University Maulana Malik Ibrahim. The results of the project execution can be categorized as quite good. Accuracy generated is calculated from the timeline of work on the software project and the timeline for the realization of the project. Case studies taken were obtained from the spelling process of learning media under one consultant in the city of Malang.

\section{References}

[1] D. . Ganesha Putri, R. Witjaksono, and M. Idawicaksakti, "Information System Design Based On Enterprise Resource Planning Using Account Payable Module Sap With Accelerated Sap Method In Pt. Len Industries (Persero)," Int. J. Innov. Enterp. Syst., vol. 1, no. 2, p. 34, 2017.

[2] M. H. Hilman, F. Setiadi, I. Sarika, J. Budiasto, and R. Alfian, "Comparative Study of ERP Implementation Methodology Case Study: Accelerated SAP VS Dantes \& Hasibuan Methodology,” J. Sist. Inf., vol. 8, no. 1, pp. 8-15, 2013.

[3] A. Terminanto and A. N. Hidayanto, "Identifying Characteristics and Configurations in Open Source ERP in Accounting Using ASAP: A Case Study on SME," in 2017 International Conference on Soft Computing Intelligent System and Information Technology (ICSIIT), 2017.

[4] S. Mamoghli, V. Goepp, and V. Botta-Genoulaz, "An approach for the management of the risk factors impacting the model-based engineering methods in ERP projects," IFAC-PapersOnLine, vol. 51, no. 11, pp. 1206-1211, 2018.

[5] U. Jayawickrama and S. Yapa, "Factors Affecting ERP Implementations: Client and Consultant Perspectives," J. Enterp. Resour. Plan. Stud., pp. 1-12, Mar. 2013.

[6] J. Zhang, D. Zage, and W. Zage, "Improving project planning/tracking for student software engineering projects through SOPPTS," in Proceedings 16th Conference on Software Engineering Education and Training (CSEE\&T 2003), 2003.

[7] Y. Yabuuchi, D. Kocaoglu, and J. Watada, "Analysis of Project Management in Software Development," in 2006 Technology Management for the Global Future PICMET 2006 Conference, 2006, pp. 2809-2814.

[8] H. E. Lam and P. Maheshwari, "Task and team management in the Distributed Software Project Management Tool," in 25th Annual International Computer Software and Applications Conference. COMPSAC, 2001. 
